\title{
biö-protocol
}

\section{Glucosinolates Determination in Tissues of Horseradish Plant}

Filomena Lelario ${ }^{1^{\star}}$, Susanna De Maria ${ }^{2}$, Rosa Agneta ${ }^{2}$, Christian Möllers ${ }^{3}$, Sabino Aurelio Bufo ${ }^{1}$ and Anna Rita Rivelli ${ }^{2}$

${ }^{1}$ Department of Sciences, University of Basilicata, Via dell'Ateneo Lucano, Potenza (PZ), Italy; ${ }^{2}$ School of Agricultural, Forest, Food and Environmental Sciences, University of Basilicata, Potenza , Italy; ${ }^{3}$ Department of Crop Sciences, Georg-August-Universität Göttingen, Göttingen, Germany

*For correspondence: filomenalelario@hotmail.com

[Abstract] Glucosinolates (GLS) are secondary metabolites mainly found in plants belonging to the Brassicaceae family, including also horseradish (Armoracia rusticana G. Gaertn., B. Mey. \& Scherb), a popular spice with a characteristic pungent flavor due to the abundance of GLS. Such compounds exhibit antibacterial, antifungal, and insecticidal activities, as well as human health properties. Therefore, it is very important to have a full understanding of their levels and profiles in plants. However, the characterization of GLS from horseradish crude extracts is a tough task, due to the complexity of the vegetal matrix and the occurrence of many GLS in trace amounts. Here we describe two alternative effective and rapid methods for GLS characterization in horseradish plants: Liquid chromatography coupled to high resolution mass spectrometry (LC-MS) for determination of intact GLS and HPLC-UV for determination of desulfo-GLS.

\section{Materials and Reagents}

1. Horseradish tissue (hypogeous and epigeous portion) (see Note 1)

2. Methanol (MeOH) (LC/MS grade) (Carlo Erba Reagents, catalog number: 414831)

3. Acetonitrile (ACN) (LC/MS grade) (Carlo Erba Reagents, catalog number: 412342)

4. Ultrapure Milli-Q water

5. Liquid nitrogen

6. Sinigrin hydrate from horseradish (99\%) (Sigma-Aldrich, catalog number: S1647)

7. Rapeseed ERM certified Reference Material containing gluconapin, 4-hydroxyglucobrassicin, glucobrassicanapin, glucobrassicin and gluconaturtiin (Sigma-Aldrich, catalog number: ERMBC367)

8. Glucoiberin (C2 Bioengineering, catalog number: 10-JS 12-05-02)

9. Glucobarbarin (C2 Bioengineering, catalog number: 18-DM 19-10-99)

10. Glucotrapeolin (C2 Bioengineering, catalog number: 16-PM 19-10-99)

11. $70 \% \mathrm{MeOH}$ (see Recipes)

\section{In addition only for intact GLS determination}

12. Formic acid (gradient grade) (Sigma-Aldrich, catalog number: F0507) 


\section{bĭ̈-protocol}

13. $0.1 \%$ Formic acid $(\mathrm{HCOOH})$ (see Recipes)

\section{In addition only for desulfo-method}

14. DEAE-Sephadex A-25 (formiate form) obtained by using DEAE-Sephadex A-25 (chloride form) (Sigma-Aldrich, catalog number: A25120) and imidazole (Sigma-Aldrich, catalog number: 56750)

15. Sulfatase type H-1 (Sigma-Aldrich, catalog number: S-9626)

16. Sulfatase type $\mathrm{H}-1$ (1 to 2.5) (see Recipes)

17. DEAE-Sephadex A-25 (formiate form) (see Recipes)

\section{Equipment}

1. Freeze Dry Systems (e.g. Labconco, model: Freezone 4.5)

2. Laboratory mill

3. Disposable $50 \mathrm{ml}$ and $15 \mathrm{ml}$ polypropylene tubes

4. $2 \mathrm{ml}$ sample vials

5. Water bath: beaker filled with water and placed on a heating device (electric hotplate or similar device).

6. Thermometer

7. Vortex mixer

8. Refrigerated centrifuge ( $50 \mathrm{ml}$ tubes) (e.g. Heraeus, model: Varifuge F)

9. Glass Pasteur pipettes

10. $0.22 \mu \mathrm{m}$ nylon filter (Whatman)

11. HPLC system with a photodiode array detector (e.g. Agilent, model: Agilent 1200 HPLC Liquid Chromatrography System)

12. HPLC 2 ml glass vials (Phenomenex, model: AR1-3910-12) with caps (Phenomenex, model: AR0-8959-13-B)

13. Liquid chromatography (LC) coupled with electrospray ionization (ESI) and high resolution mass spectrometry (MS) (e.g. Thermo Fisher Scientific, model: LC-ESI-FTICR MS)

14. Intact glucosinolates Discovery $\mathrm{C}_{18}$ column, $250 \times 4.6 \mathrm{~mm}, 5 \mu \mathrm{m}$ particle size (pore

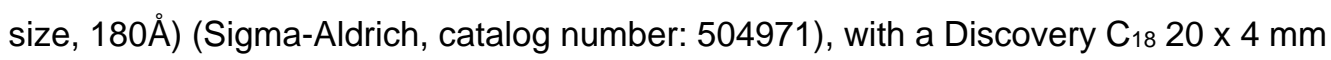
security guard cartridge (Sigma-Aldrich, catalog number: 505129)

15. Desulfoglucosinolates (Nucleodur $\mathrm{C}_{18}$ column, $125 \mathrm{~mm} \quad \mathrm{x} \quad 3 \quad \mathrm{~mm}$ ) (MACHEREY-NAGEL, catalog number: MN760051.30)

\section{Procedure}

\section{Intact GLS}

A. GLS extraction 
1. Clean plant material with distilled water and dry with paper towels. Separate roots from epigeous portion, weight and immediately freeze at $-80{ }^{\circ} \mathrm{C}$ to inhibit myrosinase activity.

2. Lyophilize the frozen tissues and grind to a fine powder using a laboratory mill. Chill roots in liquid nitrogen before the lyophilization to allow the crushing.

3. Weigh $\mathbf{2 0 0} \mathrm{mg}$ of frozen dry material in $50 \mathrm{ml}$ polypropylene tubes and place in a water bath heated with an electric hotplate at $70-80^{\circ} \mathrm{C}$ for $10 \mathrm{~min}$. During this process, carry out the following steps: After $1 \mathrm{~min}$ add $2 \mathrm{ml}$ of $70 \%$ methanol solvent and after $5 \mathrm{~min}$ mix with vortex for $20 \mathrm{sec}$.

4. At the end of 10 min remove the polypropylene tube from the water bath and mix again with vortex for $20 \mathrm{sec}$.

5. Centrifuge at $4{ }^{\circ} \mathrm{C}$ for $10 \mathrm{~min}$ at $2,400 \times g$.

6. Collect the supernatant in a disposable $15 \mathrm{ml}$ polypropylene tube by using glass Pasteur pipettes.

7. Extract again the remaining pellet with $2 \mathrm{ml}$ of $10 \%$ methanol in water bath heated with an electric hotplate at $70-80{ }^{\circ} \mathrm{C}$ for $10 \mathrm{~min}$; after $5 \mathrm{~min}$ mix with vortex for $20 \mathrm{sec}$ and the follow the same procedure from step A4-6.

8. Combine the supernatants and vortex the extract for $20 \mathrm{sec}$.

9. Filter through $0.22 \mu \mathrm{m}$ nylon filter and transfer into $2 \mathrm{ml}$ sample vials.

B. GLS detection by LC MS

1. Inject $25 \mu \mathrm{l}$ of each sample in LC-ESI-FTICR MS system equipped with Discovery $\mathrm{C}_{18}$ column, $250 \times 4.6 \mathrm{~mm}, 5 \mu \mathrm{m}$ particle size (pore size, $180 \AA$ ), with a Discovery $\mathrm{C}_{18} 20 \mathrm{x}$ $4 \mathrm{~mm}$ security guard cartridge.

Settings:

Flow rate: $1 \mathrm{ml} / \mathrm{min}$

Column temperature: $25^{\circ} \mathrm{C}$

Solvent gradient for chromatographic separation:

\begin{tabular}{|c|c|c|}
\hline Time (min) & $\begin{array}{c}\text { \% Solvent A } \\
0.1 \% \mathrm{HCOOH} \text { water }\end{array}$ & $\begin{array}{c}\text { \% Solvent B } \\
\text { ACN }\end{array}$ \\
\hline 0 & 90 & 10 \\
\hline 10 & 76 & 24 \\
\hline 12 & 40 & 60 \\
\hline 15 & 90 & 10 \\
\hline 20 & 90 & 10 \\
\hline
\end{tabular}

Connect the LC system to the mass spectrometer by a laboratory-made splitter with a split ratio of 1:4 after the analytical column to allow $200 \mu \mathrm{l} / \mathrm{min}$ to enter the ESI source. 


\section{bĭ̈-protocol}

2. Perform full-scan experiments in both the linear trap and the ICR cell. Collect data in profile mode in the range of $m / z 50-1,000$ by setting:

Ionization mode: negative

Resolution: 100.000 (FWHM) at $m / z 400$

ESI needle voltage: $-4.60 \mathrm{kV}$

Capillary voltage: $-22 \mathrm{~V}$

Temperature of the heated capillary: $350^{\circ} \mathrm{C}$

Sheath gas $\left(\mathrm{N}_{2}\right)$ flow rate: 80 (arbitrary units)

In these conditions GLS elute with a retention time and molecular exact mass to charge ratio as reported in the following table (Agneta et al., 2012; Agneta et al., 2014):

\begin{tabular}{llcl}
\hline & Molecular & Monoisotopic exact & \\
formulae & value as $[\mathrm{M}-\mathrm{H}]^{-}$ & $\mathrm{t}_{\mathrm{R}}$ \\
& & $(\mathrm{m} / \mathrm{z})$ & \\
\hline
\end{tabular}

\begin{tabular}{lccc} 
3-(Methylsulfinyl)propyl-GLS & $\mathrm{C}_{11} \mathrm{H}_{21} \mathrm{NO}_{10} \mathrm{~S}_{3}$ & 422.02549 & 4.3 \\
2-Propenyl-GLS & $\mathrm{C}_{10} \mathrm{H}_{17} \mathrm{NO}_{9} \mathrm{~S}_{2}$ & 358.02720 & 4.4 \\
2-Methylsulfonyl-oxo-ethyl-GLS & $\mathrm{C}_{10} \mathrm{H}_{17} \mathrm{NO}_{12} \mathrm{~S}_{3}$ & 437.98402 & 4.6 \\
3-Butenyl-GLS & $\mathrm{C}_{11} \mathrm{H}_{19} \mathrm{NO}_{9} \mathrm{~S}_{2}$ & 372.04285 & 5.5 \\
1-Methylpropyl-GLS & $\mathrm{C}_{11} \mathrm{H}_{21} \mathrm{NO}_{9} \mathrm{~S}_{2}$ & 374.05850 & 6.2 \\
2-Methylpropyl-GLS & $\mathrm{C}_{11} \mathrm{H}_{21} \mathrm{NO}_{9} \mathrm{~S}_{2}$ & 374.05850 & 6.4 \\
4-Mercaptobuthyl-GLS & $\mathrm{C}_{11} \mathrm{H}_{21} \mathrm{NO}_{9} \mathrm{~S}_{3}$ & 406.03057 & 6.5 \\
7-Methylsulfinylheptyl-GLS & $\mathrm{C}_{15} \mathrm{H}_{29} \mathrm{NO}_{10} \mathrm{~S}_{3}$ & 478.08808 & 7.3 \\
4-Hydroxyindol-3-ylmethyl-GLS & $\mathrm{C}_{16} \mathrm{H}_{20} \mathrm{~N}_{2} \mathrm{O}_{10} \mathrm{~S}_{2}$ & 463.04866 & 7.4 \\
Unidentified & ${ }^{\circ}{ }{ }_{16} \mathrm{H}_{20} \mathrm{~N}_{2} \mathrm{O}_{10} \mathrm{~S}_{2}$ & 463.04866 & 7.5 \\
4-hydroxyindol-3-ylmethyl-GLS & & & \\
2(S)-Hydroxy-2-phenylethyl-GLS & $\mathrm{C}_{15} \mathrm{H}_{21} \mathrm{NO}_{7} \mathrm{~S}$ & 438.05341 & 7.8 \\
and/or 2(R)-Hydroxy-2-phenylethyl-GLS & $\mathrm{C}_{12} \mathrm{H}_{21} \mathrm{NO}_{9} \mathrm{SO}_{2}$ & 386.05850 & 7.8 \\
4-Pentenyl-GLS & $\mathrm{C}_{14} \mathrm{H}_{19} \mathrm{NO}_{9} \mathrm{~S}_{2}$ & 408.04285 & 8.5 \\
$\begin{array}{l}\text { Benzyl-GLS } \\
\text { Indol-3-ylmethyl-GLS }\end{array}$ & $\mathrm{C}_{16} \mathrm{H}_{20} \mathrm{~N}_{2} \mathrm{O}_{9} \mathrm{~S}_{2}$ & 447.05375 & 10.3 \\
2-Phenylethyl-GLS & $\mathrm{C}_{15} \mathrm{H}_{21} \mathrm{NO}_{9} \mathrm{~S}_{2}$ & 422.05850 & 12.1 \\
4-Methoxyindol-3-ylmethyl-GLS & $\mathrm{C}_{17} \mathrm{H}_{22} \mathrm{~N}_{2} \mathrm{O}_{10} \mathrm{~S}_{2}$ & 477.06431 & 12.7 \\
7-Methylthioheptyl-GLS & $\mathrm{C}_{15} \mathrm{H}_{29} \mathrm{NO}_{9} \mathrm{~S}_{3}$ & 462.09317 & 16.7 \\
\hline
\end{tabular}

Note: It is possible to use the extracts to quantify GLS by preparing a calibration curve for each GLS using a series of dilution and calculating the area under the peak of each compound. 


\section{bio-protocol}

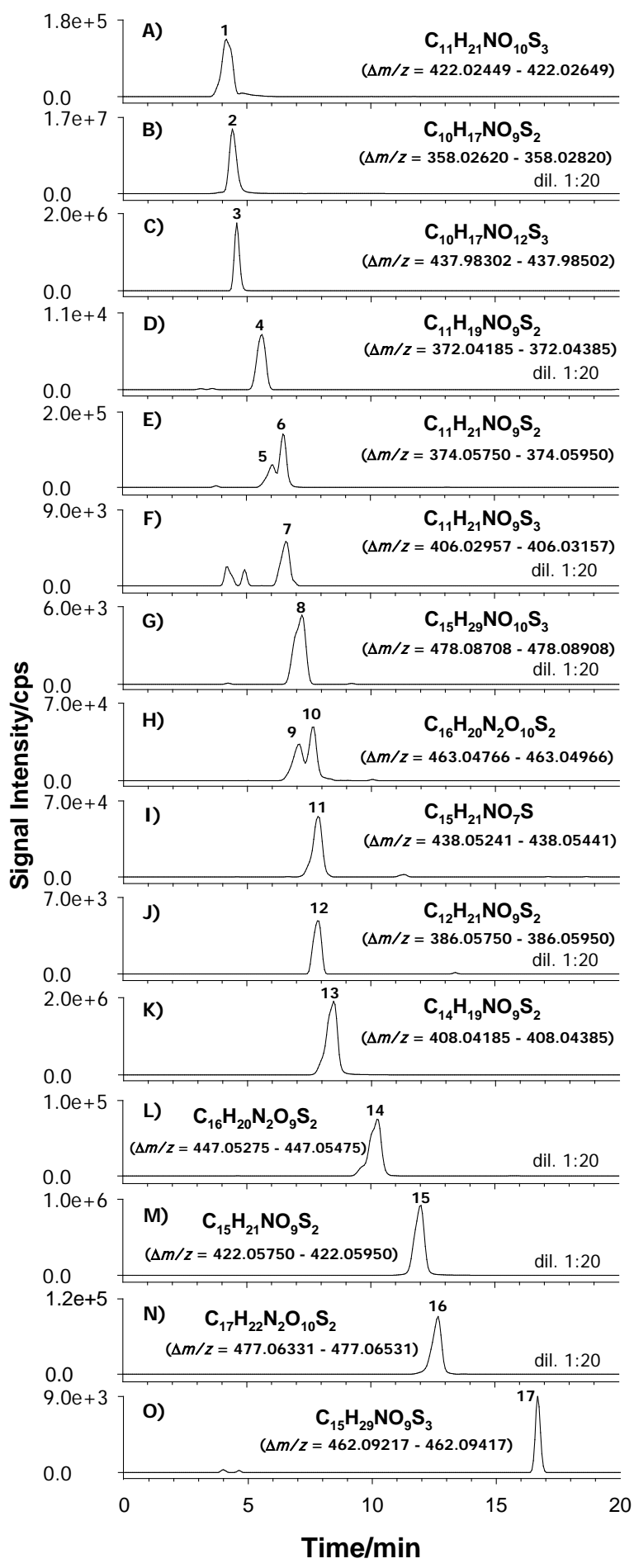

Figure 1. Example of eXtracted lon Chromatograms (XICs) using high resolution LC-ESI-FTICR MS acquired in negative ion mode of root crude extract of $A$. rusticana. The ions monitored are displayed in each trace (plots A-O) and correspond to the most abundant deprotonated molecules, $[\mathrm{M}-\mathrm{H}]^{-}$, using a restricted window of $\pm 0.0010 \mathrm{~m} / \mathrm{z}$ unit centered around each selected ion. Peak numbers in bold correspond to: $\quad$ (1) 3-(methylsulfinyl)propyl-GLS;

(2) 2-propenyl-GLS; 


\section{bĭo-protocol}

2-methylsulfonyl-oxo-ethyl-GLS; (4) 3-butenyl-GLS; (5)* 1-methylpropyl-GLS; (6)*

2-methylpropyl-GLS; (7)* 4-mercaptobuthyl-GLS; (8)* 7-methylsulfinylheptyl-GLS; (9)

4-hydroxyindol-3-ylmethyl-GLS; (10) unidentified isomer of 4-hydroxyglucobrassicin; (11)

2(S)-hydroxy-2-phenylethyl-GLS and/or 2(R)-hydroxy-2-phenylethyl-GLS;

4-pentenyl-GLS; (13) benzyl-GLS; (14) indol-3-ylmethyl-GLS; (15) 2-phenethyl-GLS; (16) 4-methoxyindol-3-ylmethyl-GLS; (17)* 7-methylthioheptyl-GLS (peaks with asterisk are tentatively assigned). The XIC signals of some peaks were acquired using a sample extract diluted 1:20 with the mobile phase. In bold are indicated also the molecular formula and the range of monoisotopic value as [M-H] ${ }^{-}$ion $(\Delta \mathrm{m} / \mathrm{z})$ (Agneta et al., 2014).

\section{Desulfo GLS}

A. GLS extraction

1. Follow the procedure of intact GLS step A1-8.

2. Transfer $500 \mu \mathrm{l}$ of the extract on the top of a $20 \mathrm{mg}$ of Sephadex DEAE-A 25 (shortened Pasteur pipet) in the formiate form.

3. Wash the column twice with $1 \mathrm{ml}$ of deionized water

4. Add $100 \mu \mathrm{l}$ of sulfatase type $\mathrm{H}-1$ diluted 1 to 2.5 with water to achieve the desulfation and incubate overnight at $39^{\circ} \mathrm{C}$ (minimum $16 \mathrm{~h}$ ) (Möllers et al., 1999)

5. Elute desulfatated GLS with $3 \times 500 \mu \mathrm{l}$ deionized water and collect in $15 \mathrm{ml}$ polypropylene tubes.

6. Vortex the sample for $20 \mathrm{sec}$.

7. Filter through $0.22 \mu \mathrm{m}$ nylon filter and transfer into $2 \mathrm{ml}$ sample vials.

B. GLS detection by HPLC

1. Inject $25 \mu$ l of each sample in HPLC system equipped with Nucleodur $\mathrm{C}_{18}$ column, 125 $\mathrm{mm} \times 3 \mathrm{~mm}$.

Settings:

Flow rate: $0.6 \mathrm{ml} / \mathrm{min}$

Column temperature: $35{ }^{\circ} \mathrm{C}$

UV detection: 229

Solvent gradient for chromatographic separation:

\begin{tabular}{|c|c|c|}
\hline Time (min) & $\begin{array}{c}\text { \% Solvent A } \\
\text { Water }\end{array}$ & $\begin{array}{c}\text { \% Solvent B } \\
\text { ACN }\end{array}$ \\
\hline 0 & 99 & 1 \\
\hline 20 & 80 & 20 \\
\hline 25 & 80 & 20 \\
\hline 22 & 99 & 1 \\
\hline
\end{tabular}




\section{biö-protocol}

http://www.bio-protocol.org/e1562 Vol 5, Iss 16, Aug 20, 2015

In these conditions GLS elute with a retention time as reported in the following table:

\begin{tabular}{lcc}
\hline Chemical name & $t_{R}$ & $\begin{array}{r}\text { Relative resp } \\
\text { factor }\end{array}$ \\
& & \\
3-(Methylsulfinyl)propyl-GLS & 2.8 & 1.07 \\
2-Propenyl-GLS & 4.3 & 1.00 \\
3-Butenyl-GLS & 7.3 & 1.11 \\
1-Methylpropyl-GLS and/or & 8.9 & $1.00^{\mathrm{b}}$ \\
2-Methylpropyl-GLS & 8.9 & $1.00^{\mathrm{b}}$ \\
2(S)-Hydroxy-2-phenylethyl-GLS & 10.1 & \\
and/or 2(R)-Hydroxy-2-phenylethyl-GLS & & $0.98^{\mathrm{c}}$ \\
4-Pentenyl-GLS & 10.9 & \\
Benzyl-GLS & 11.8 & 1.15 \\
Indol-3-ylmethyl-GLS & 13.9 & 0.95 \\
2-Phenylethyl-GLS & 16.1 & 0.29 \\
4-Methoxyindol-3-ylmethyl-GLS & 16.5 & 0.95 \\
\end{tabular}

aThe response factors values used for the desulfated glucosinolates quantification as reported in EN ISO 9167-1 (1992), with except of following desulfated molecules: 1-methylpropyl-GLS, 2-methylpropyl-GLS and 2(S)-hydroxy-2-phenylethyl-GLS and/or 2(R)-Hydroxy-2-phenylethyl-GLS

${ }^{\mathrm{b}}$ Response factor of 2-propenyl-GLS as desulfated molecules used for the relative quantification

'Experimental response factor determinate by using the 2(S)-hydroxy-2-phenylethyl-GLS in comparison to 2-propenyl-GLS as desulfated molecules (see Note 2)

\section{$\underline{\text { Notes }}$}

1. Plant tissues were collected from a field collection of the Institute of Plant Genetics, National Research Council, Thematic Centre for the Preservation of Mediterranean Biodiversity, located in Policoro (MT) (40 17' 30" N, 16 65' 16" E), where many accessions of horseradish, previously collected from various villages of the internal areas of the Basilicata region, are maintained and vegetatively propagated (for details see Sarli et al., 2012).

2. It is possible to use the extracts to quantify desulfo GLS by preparing a calibration curve for each GLS by using a series of dilution and calculating the area under the peak of each compound.

It is also possible to quantify desulfo GLS by using the response factors reported in the table above, if you add an internal standard after step A3 (Procedure A), and by applying the following formula:

$\mu$ mol $\quad$ Areadg $\times \mathrm{RF}_{\mathrm{dg}} \times \mathrm{n}$ 


\section{biö-protocol}

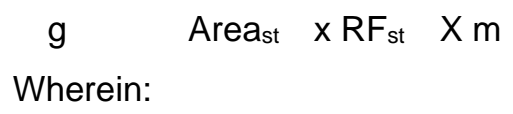

Wherein:

Areadg is the peak area of the desulfoglucosinolate, Areast is the peak area of internal standard, RFdg is the response factor of the corresponding desulfoglucosinolate, $\mathrm{RF}_{\mathrm{st}}$ is the response factor of the internal standard, $\mathrm{n}$ is the quantity, in $\mu \mathrm{mol}$, of the internal standard added to the sample, $\mathrm{m}$ is the mass, in $\mathrm{g}$, of the sample.

\section{Recipes}

1. $70 \% \mathrm{MeOH}$

$70 \mathrm{ml}$ of $\mathrm{MeOH}$

$30 \mathrm{ml}$ of Milli-Q water

2. $0.1 \%$ Formic acid $(\mathrm{HCOOH})$

$1 \mathrm{ml}$ of Formic acid

$999 \mathrm{ml}$ of Milli-Q water

3. Sulfatase type $\mathrm{H}-1$ (1 to 2.5 )

$1 \mathrm{ml}$ of sulfatase type $\mathrm{H}-1$

$1.5 \mathrm{ml}$ of Milli-Q water

4. DEAE-Sephadex A-25 (formiate form)

Convert the chloride form to the formiate form by adding for each column $500 \mu \mathrm{l}$ of $6 \mathrm{mM}$ imidazole formiate (dissolve $40 \mathrm{~g}$ imidazole in $100 \mathrm{ml} \mathrm{30 \%} \mathrm{formic} \mathrm{acid)} \mathrm{and} \mathrm{then} \mathrm{rinsing}$ the column with water.

\section{References}

1. Agneta, R., Lelario, F., De Maria, S., Möllers, C., Bufo S. A. and Rivelli A. R. (2014). Glucosinolate profile and distribution among plant tissues and phenological stages of field-grown horseradish. Phytochem 106: 178-187.

2. Agneta, R., Rivelli, A. R., Ventrella, E., Lelario, F., Sarli, G. and Bufo, S. A. (2012). Investigation of glucosinolate profile and qualitative aspects in sprouts and roots of horseradish (Armoracia rusticana) using LC-ESI-hybrid linear ion trap with Fourier transform ion cyclotron resonance mass spectrometry and infrared multiphoton dissociation. J Agric Food Chem 60(30): 7474-7482.

3. EN ISO 9167-1 (1992). Rapeseed-Determination of glucosinolates content-Part 1: Method using high-performance liquid chromatography.

4. Möllers, C., Nehlin, L., Glimelius, K. and Iqbal M. C. M. (1999). Influence of in vitro culture conditions on glucosinolate composition of microspore-derived embryos of Brassica napus. Physiol Plantarum 107(4): 441-446.

5. Sarli, G., De Lisi, A., Agneta, R., Grieco, S., Ierardi, G., Montemurro, F., Negro, D., Montesano, V. (2012)._Collecting horseradish (Armoracia rusticana, Brassicaceae): 
Resour Crop Ev 59(5): 889-899. 